\title{
Will the rest of the world live like America?
}

\author{
Jesse H. Ausubel ${ }^{*}$ \\ Program for the Human Environment, The Rockefeller University, 1230 York Avenue, \\ New York, NY 10021-6399, USA
}

\begin{abstract}
Living like America means producing and consuming at or near the level of the present top consumer. For material well-being as well as equity, many wish and work for a world in which high economic activity pervades. Others fear environmental harm from the product of global population times the affluence of America. I ask: Has the world ever had uniform income at the level of the top consumer? Do swift, cheap transport and communication equalize income? Historically, incomes vary for the reason that income crowns the successful completion of a series of multiplicative tasks, causing a skewed distribution. Despite lessening physical obstacles, social wrinkles maintain distributions broad and skewed, as the diffusion of railroads, cars, and electricity shows. As incomes rise, however, economic, social, and environmental requirements and capacities grow to lessen harm. We are likely to live in a cleaner world, with sustained inequalities.
\end{abstract}

(C) 2004 Elsevier Ltd. All rights reserved.

Keywords: Zipf; Golden ratio; Inequality; Sustainable development

\section{Introduction}

Multiplication of the affluence of all to the level of Americans awakens hope in some and frightens others. The hopeful envision multiplication and diffusion of goods, communication, and mobility until the rest of the world lives at the level of its top consumers, today Americans. The fearful envision the Chinese multiplying their motor vehicles to 1 billion, demanding five times the amount of gas the Americans now guzzle, and creating lethal air, furibund congestion, and struggles for resources. Multiplying present American consumption by 20 (about the ratio of

\footnotetext{
${ }^{*}$ Tel.: +1-212-327-7917; fax: +1-212-327-7519.

E-mail address: ausubel@rockefeller.edu (J.H. Ausubel).
} 
world to American population) conjures images of an exhausted globe, roasting climate, and so, a collapsed civilization.

In this essay, I explore whether in, say, 2050 or 2100 , every person outside the US will produce and consume at or near the level of the top consumer. I ask whether the world ever had a uniform income at the level of the top consumer. I ask whether swift transport and instant communication equalize income.

\section{A brief history of skewed incomes}

My answers begin with history and theories of the skewed nature of complex achievements and diffusion. In a victory of hope over experience, some envision a break between past and future. Looking back over hundreds and thousands of years in diverse societies, we find few disjunctures. Nevertheless, many prophets have foretold them. A score of years before the Battle of Waterloo, the philosopher Saint-Etienne wrote, "Everything announces an age in which that madness of nations, war, will come to an end" [1]. A score of years before the skyrocketing price of the 1970s oil crisis, the managing director of the International Monetary Fund announced that "in all likelihood world inflation is over" [1]. I am skeptical that rules have broken and something is new under the sun at the beginning of the 21 st century.

A belief in the stability of the rules of the game prompts the straightforward question: "Has the world ever lived at the level of its leading economic entity?" For example, replacing America with other former top consumers, I might ask if once upon a time the rest of the world lived like Imperial Rome or Victorian London.

Rome spread from Gibraltar to Mesopotamia, from upper Egypt to Hadrian's Wall [2]. So did Roman temples and amphitheaters, and paving and smelting. Roman coins spread, too, but not Roman incomes, although incomes surely did rise widely. In the hinterland, income remained at a fraction of the metropole's, and in the metropole itself the poor got only the crumbs of the rich.

Railroads symbolized Victorian Britain. Nineteenth century Britons built not only their own railroads but also financed and constructed them for much of the rest of the world. However, the rails were never laid as densely anywhere else as in Britain. Had they achieved the British spatial density in broader lands, their demands for steel, coal, and wood might have exhausted supplies. Starting first, Britain built a rail network, with attendant costs and benefits, one-third denser than in Germany, almost twice as dense as in France, four times denser than in the US, and 10 or more times denser than in other countries apparently comparable at the outset of the railroad era [3].

This brief history convinces us that wealth and development have always been skewed. As Fig. 1 shows, not all Americans live like Americans. Most live well below the top consumers, represented by those paying taxes on more than $\$ 100$ thousand per year. If the Internal Revenue Service detailed income categories above \$1 million, the tail would skew upward much farther. Most people lived well below Imperial Romans and Victorian Londoners, just as we today mostly live 


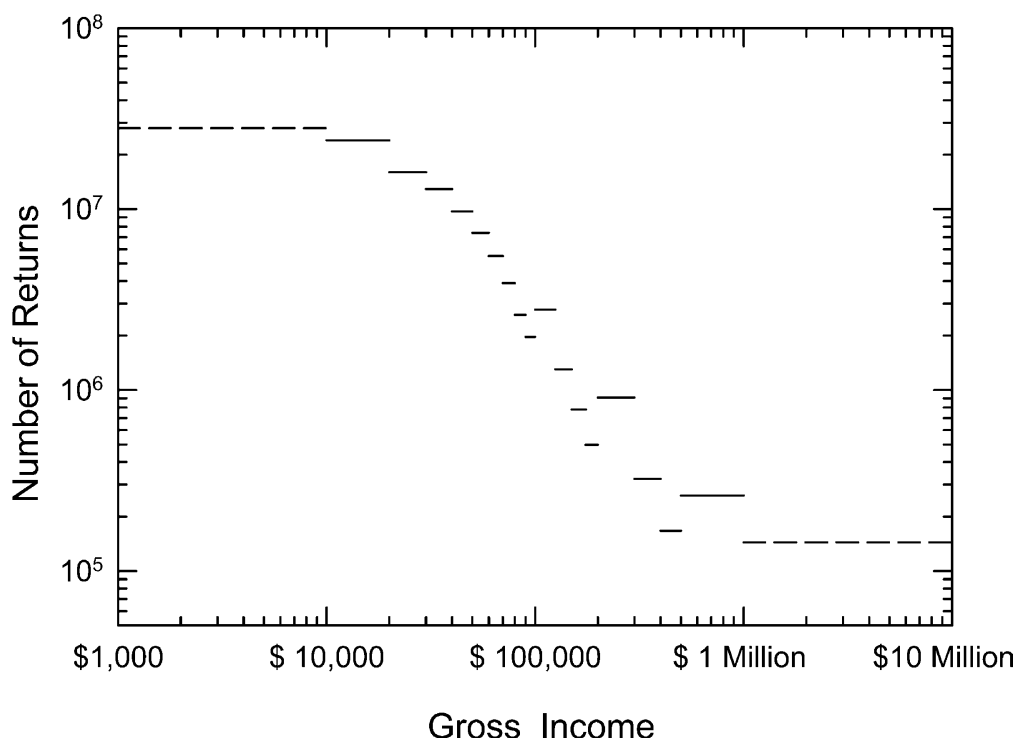

Fig. 1. Log-log plot of reported gross income in US tax returns, 1997. In this year, about 93 million returns reported income below $\$ 50,000$, about 22 million between $\$ 50,000$ and $\$ 100,000$, and 7 million above $\$ 100,000$, a sharply skewed distribution. Each line represents the number of returns over the income range indicated. For example, the second line from the top shows 24 million returns with gross income between $\$ 10,000$ and $\$ 20,000$. The dashed lines cover the initial range of income under $\$ 10,000$ and the top range of $\$ 1,000,000$ or more. Source: data from IRS http://www.irs.gov.

below the long tail skewed to the right. The hope or fear that all will live like present Americans requires universal convergence on one high income, a single point, and is defeated by the persistent and broadly skewed distributions of income. Some famous cases explain why.

\section{The statistics of skewed income}

Many observers are jealously fascinated that in any fairly homogeneous and integrated region, the income of, say, the tenth in the scale of riches is roughly one-tenth the wealth of the richest. Thus in America during the 1990s, the second richest, Warren Buffet had about half the assets of Bill Gates, the third richest had about one-third, and so on down to the 10,000th and 100-millionth richest.

In general, when frequencies are distributed in such a harmonic series, they are said to follow Zipf's Law, named for a collector of statistical oddities, George K. Zipf (1902-1950). Zipf discovered his law while counting word frequencies in languages as diverse as Chinese, Greek, Gothic, English, and Nootka. In all those diverse languages, if he plotted the frequency of words from common to rare, their frequency on double-logarithmic or log-log coordinates fell straight at $45^{\circ}$. The same law, or close relatives, rules distributions of items as diverse as musical pieces played in concert, 
subjects in newspapers, distances between marrying couples, publications of scientists - and income $[4,5]$.

Studying income, Vilfredo Pareto (1848-1923) collected statistics on wealth in many countries and historical eras [6]. The statistics convinced Pareto that a law regulated the distribution of income. In all places and times with a stable economy and sufficiently high income, the frequency of individual incomes fell along a straight line on $\log -\log$ coordinates, echoing the distributions of all those other things like words and music. The frequencies of incomes fell with a slope near -1.5 on $\log -\log$ coordinates. On the low end at the left of the distribution, the distribution did not reach zero but stopped abruptly where the wolf was at the door, threatening survival. Call that the "wolf point".

The econometrician N.O. Johnson confirmed Pareto's story for American incomes from 1914 to 1933 [7], and we found the situation little changed by 19921994 (Fig. 2). Analysis by the World Bank, established more than a half century ago to lift and even global development, finds global distribution of income in 1993 still classically skewed [8]. The persistence of an income distribution so skewed in Fig. 1 that it requires the logarithmic transformation of Fig. 2 to straighten it

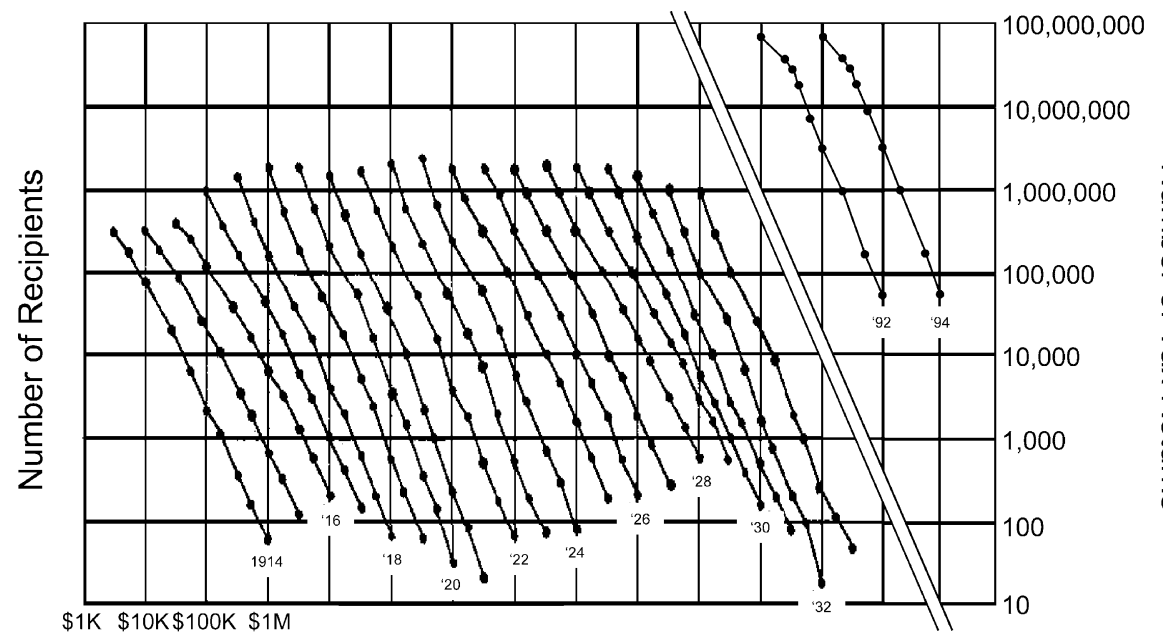

\section{Income Scale}

Fig. 2. A shifted log-log display of US income distributions, 1914-1933 and 1992-1994. Plots from 1914-1933 copied from Ref. [7]. Plots for 1992-1994 constructed from Internal Revenue Service data on adjusted gross income by numbers of returns (http://www.irs.gov). For any represented year, the line is plotted from the lowest point to the right, showing the number of returns reporting income of \$1million or more, back to $\$ 100,000$, and $\$ 10,000$. Thus, for example, in the 1914 string of points slightly under 100 recipients reported $\$ 1$ million income (bottom point on 4th vertical line), about 3000 for $\$ 100,000$ (point on 3rd vertical line), and about 100,000 for $\$ 10,000$ (point on 2 nd vertical line). In 1992, about 100,000 returns were filed for more than $\$ 1$ million, about 8 million for $\$ 100,000$, and about 80 million over $\$ 10,000$. While the economy fluctuates, income remains skewed. 
constitutes a persistent obstacle to the crowning success of everyone living like the top earners.

\section{A crowning success as a multiplication of essential tasks}

What causes the surprisingly persistent inequality of skewness and obstacle to the crowning success of a top income? The engineer and co-inventor of the transistor, William Shockley (1910-1989) described crowning success in science in a way that explains the skewness of incomes as well as scientific achievement.

Many achievements require successfully connecting the links of a chain. In 1957, Shockley [9] noted that publishing a technical paper requires connecting links to (1) choose a good problem; (2) work on it; (3) recognize a worthwhile result; (4) decide when to stop; (5) draft a report adequately; (6) profit constructively from criticism; (7) submit the paper; and (8) survive referees' objections. One might separate the chain of achievement into more or different links, but the chain clearly has several links. Critically, failure in any link means failure to reach the top. Crowning success requires success with every link, and if the probability of success in each of Shockley's eight links is $50 \%$, a crowning success is as rare as eight straight heads in a coin toss. The probabilities at each step do not add to success, they multiply.

Raising the probability of succeeding at each of the essential, separate links by the slender distance from $50 \%$ to $55 \%$ doubles the chance of final publication. And raising the probability of success of each link by half, to $75 \%$, lifts productivity $2500 \%$. The $2500 \%$ difference between 4 and 100 papers is a career, the difference between publishing to earn a doctorate and a life's work.

The steep frequency distribution of scientific productivity was first presented by Alfred J. Lotka (1880-1949), who analyzed publications in physics up to 1900 and in chemistry between 1907 and 1916 [10]. Exploring into the 1970s, Derek de Solla Price (1922-1983) affirmed that the slope of the research enterprise had not flattened during the 20th century [11]. In the 1990s, researchers published myriad papers but, as usual, most authored just a few. While Swedish society constrains income in various ways, Swedish scientists publish unequally, like Americans.

Bias against women may offer another skewing example, vexing for many occupations. In a simulation of an eight-level organization with a small promotional bias (5\%) against women at each level, psychologist R.F. Martell and colleagues reported that women occupied $58 \%$ of positions at the bottom but only $29 \%$ at the top [12]. When bias begins in secondary school and continues in higher education and the workplace, few of the disfavored will join enough links for a top career.

The binomial distribution formed by raising probabilities of success and failure to the power of the number of trials fits the success of tossing runs of heads when tossing a coin. When the probability of success at each toss is not the 50/50 of a coin but lower, the binomial is skewed up from frequent failure during a series to the rare achievement of serial, crowning success. Where low probabilities multiply rather than add, the skewed binomial distribution should logically fit the number of publications or the incomes of Fig. 1, and their logarithms may sometimes approach a bell-shaped normal distribution that can be transformed into straight 
lines like Fig. 2. When the logarithms of income rather than incomes themselves are normally distributed, the distribution is called lognormal. When probabilities multiply rather than add, they make a power of difference.

Physicists Elliott Montroll and Wade Badger used anecdotes to contrast the additive or linear events that cause symmetrical distributions against the multiplicative or nonlinear events that cause skewed ones to be fit by logarithmic transformation [13]. They illustrated the additive with "The shin bone is connected to the knee bone, the knee bone is connected to the thigh bone, the thigh bone is connected to the hip bone...." The addition of bones makes a bell-shaped normal distribution of heights with roughly as many individuals taller as shorter than the crowd of people in the middle. Among adults, the chance of meeting someone whose bones add to a height 50\% taller than yours is finite and tiny, while the chance of meeting someone 10 times your height is certainly zero.

In contrast, Montroll and Badger illustrated multiplication of links that skew distributions by "For want of a nail, a shoe was lost; for want of a shoe, the horse was lost; for want of a horse, a knight was lost; for want of a knight, a battle was lost; for want of a battle, a kingdom was lost. All because of a nail." A skewed distribution with a long tail fits kingdoms won.

For producing wealth and living like top consumers, consider eight other links: (1) adequate brain, (2) essential education, (3) ambition for wealth, (4) determination, (5) communication and networking skills, (6) willingness to take risks, (7) being in the right place, and (8) working at the right time. The chance of meeting someone with 10 times your income is not zero. The lognormal distribution of logarithms of income normally distributed in a bell-shape may fit the skewed frequency of crowning successes at the end of links.

Although the lognormal can fit some skewness, even it may not reach high enough because people at the very top operate differently [14]. While most earn wages that multiply as they succeed along the links, those at the very top frequently lever their income through speculation in commodity futures on margins. At the top of small businesses, bosses organize laborers to lever their income. In laboratories, graduate students and post-doctoral associates slavishly lever publications for the lab head.

Although charity and transfer payments may temper the skewness of income distribution, the linked tasks whose probabilities multiply persistently lift only a few to the highest income. The success of Americans is at the top of a chain of multiplicative tasks. And multiplication makes a skewed distribution that keeps people around the world living differently and not like Americans, or once upon a time like Romans or Britons.

\section{Will swift transport and communication equalize income?}

If people were not uniformly successful once upon a time, does technology make it possible for all to live like Americans in the future? By surmounting barriers of space and time and easing diffusion of innovation, will technology allow all to live alike and like Americans? 
By diffusion of innovation I refer, like the Swedish geographer Torsten Haegerstrand, to the origin and dissemination of cultural novelties [15]. Twentieth century novelties included nuclear power, integrated circuits, satellites, and cellphones as well as aircraft, penicillin, and hybrid corn. The chain from invention to use of such novelties illustrates how profoundly social and institutional innovations matter: universities to teach; laboratories for research; financial systems for capital; entrepreneurs to translate ideas into goods and services; and governments to encourage fairness and confidence.

Into the 20th century, physical spaces, such as oceans and mountains, often stopped diffusion. Before 1492, the isolation of horses, wheels, and gunpowder in one hemisphere and corn, tomatoes, and potatoes in another proved the past importance of physical barriers. And the age of explorers showed how technology could lower the barriers. In the 21 st century, swift and easy communication would seem ready to hurdle the physical space impeding diffusion. Fifty years ago Haegerstrand conjectured that air travel and the ability to transmit and receive television within the reach of everyone would shrink the world to a "one point society". Now that National Geographic broadcasts pictures of the far corners and astronauts photograph the entire sphere, social barriers have replaced physical barriers that impede spreading innovation that would make all live alike. With half the world's people knowing what Big Macs are and the other half waiting to make their first phone call, will everybody live alike when everybody has made a phone call?

\section{Human barriers still slow diffusion}

As it is turning out, money and especially time still prevent one individual from meeting everyone. And individuals have different willingness to venture. Innovation still must cross a wrinkled economic, technological, and cultural landscape. An entire population does not simultaneously accept an innovation. Rather, individuals gradually adopt it. Because information about most innovations is generally available promptly, the wrinkles must be those Haegerstrand proposed. People have an array of delaying mechanisms. After first learning about an innovation, some promptly accept it and some put it off. Some delay forever and thus conserve diversity.

Sometimes money is the delaying mechanism. Money may delay a doctor acquiring an expensive instrument. But, of course, for a new hairstyle, money would not matter much. Clearly, an uneven array of delaying mechanisms makes acceptance faster with some people, places, and innovations than with others.

When innovation spreads, it often passes through social fibers. Some fibers may be composed of the same occupations (chefs), ages (teenagers), or education (Yale graduates). Innovations overcome physical space by flowing along social fibers. Haegerstrand called such flow a "neighborhood" effect and illustrated it with the diffusion of bovine tuberculosis control from farmer to farmer.

Nevertheless, teenagers in Sudan, without MTV and with another religion, may learn slowly to wear their caps backwards. Haegerstrand argued that the neighborhood fibers for diffusing innovation are logical only if we turn from public to 
private information, especially face-to-face conversation. The dominance of private talk has even been confirmed for professional managers whose decisions are allegedly guided by sheaves of calculations [16]. Few people simply accept an innovation upon first learning of it, whether barred by rational economic considerations or habitual aversion to change. In fact, the spread of information appears to be a separate and often faster process than the spread of conviction or adoption. The neighborhood called Iowa farmers took about 6 years from hearing about hybrid corn to using it (Fig. 3).

Frequent contact with early birds inclines a person to accept an innovation. Testimonials about personal acceptances encourage more acceptances, something understood by evangelists in public conversions and simulated by advertisers with endorsements. The scarcity of speedy adopters resembles the rarity of the wealthy and the frequently published, all explained by the multiplication of probabilities of a chain of information, resources, experimental disposition, and especially personal contact. All make a skewed distribution of adoption.

Notwithstanding new travel and communication technologies, time and money budgets continue hindering individual contacts. Although living in a society implies that people are regularly in motion, every individual moves mostly in a neighborhood, dwelling in the center and frequenting nodes of work, shopping, recreation, and friends. Movements are inseparable from both the fleeting and more perma-

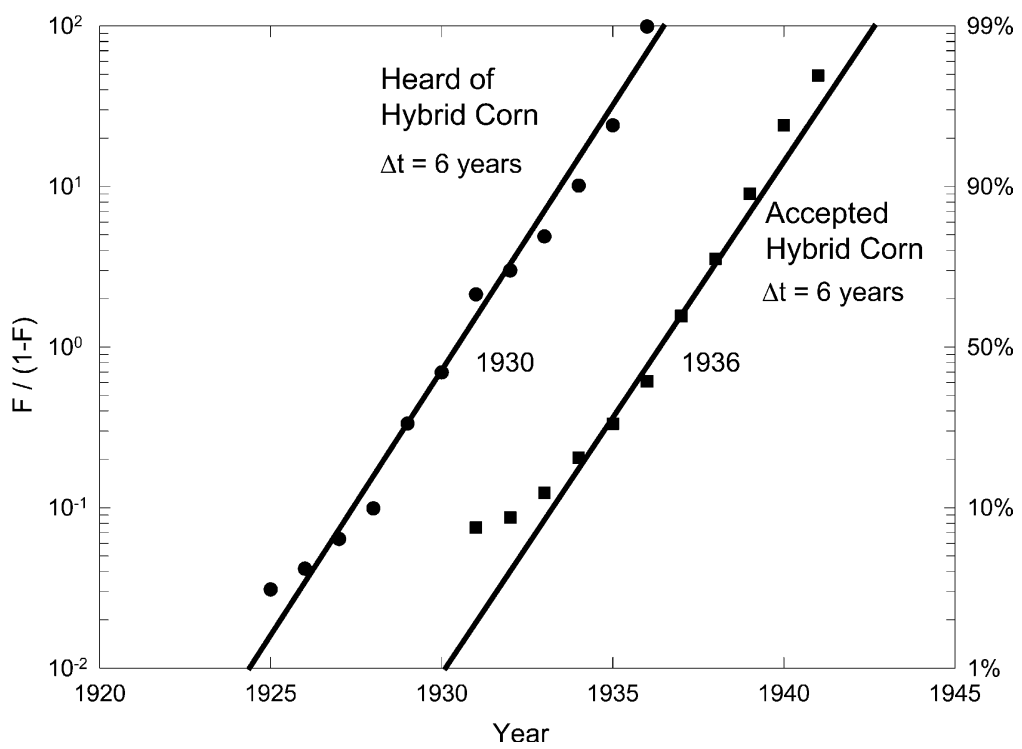

Fig. 3. Diffusion of hybrid corn innovation in Iowa. The straight lines are logistic curves fitted to the data presented in a linear transform (normalized to $100 \%$ completion of the process). $F$ is fraction of process completed. The time constant or $\Delta t$ required for the process to go from $10 \%$ to $90 \%$ completion in each case was 6 years. The processes of learning and adoption proceeded in parallel 6 years apart. Source: data from Griliches [31]. 
nent contacts between an individual and fellows that largely permit diffusion. Although wealth enables wider ranges, since the invention of language the number of people constituting our immediate neighborhood remains unchanged with a maximum near 150 people [17]. Because each relationship requires some periodic chatter, time simply does not permit maintaining a wider neighborhood. Despite the technology of real glass fibers and the social fibers of neighborhoods, such social wrinkles as finding the time to keep one's 150 friendships in repair still hinders diffusion.

Wrinkles persist along a time line, too, as explained by economist Joseph Schumpeter in his analysis of business cycles [18]. Clusters of major technologies, for example, tend to diffuse synchronously within time boxes of about 50 years, with delays or halts due to wrinkles of recession [19]. Markets rise, progressively saturate, and recede. Railroad infrastructures, as we shall see, reached saturation and slowed worldwide in the 1920s. Then innovation and entrepreneurship reopened the game for a new spurt of auto and air transport. The wrinkles of intervening recession interrupt swift adoption during booms. Wrinkles in time join physical and social barriers in slowing progress along the chain of diffusion.

\section{Skewed electricity, autos, and rails}

Three examples of multiplied probabilities on the way to adoption illustrate how links and wrinkles keep crowning success skewed even as humans apparently keep smoothing the globe. We begin with passenger car diffusion in America, Britain, Japan, and Brazil (Fig. 4). Going first, Americans took long while they learned to

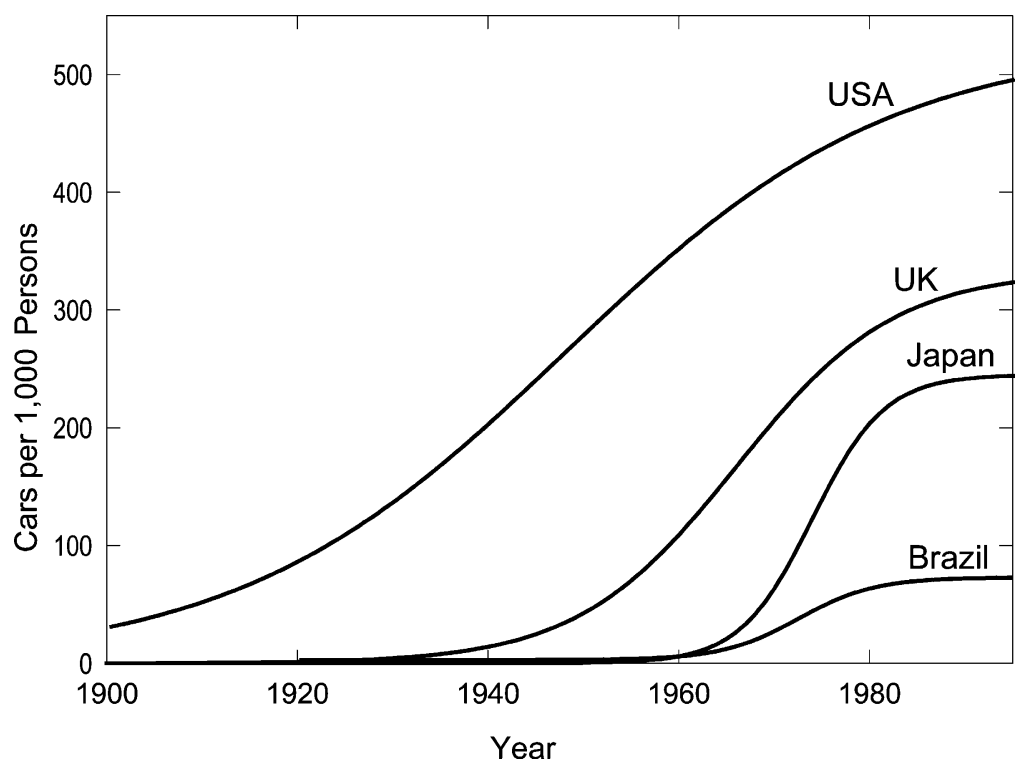

Fig. 4. Passenger car diffusion in four countries. Source: data from Gruebler [3]. 
assemble cars economically on an assembly line and build gas stations and pave highways across a continent. Going first, they also acquired the most cars per 1000 people. The pace quickened in Britain and even more in Japan. Brazil, arriving late, rose quickly and, like the others, saturated or leveled off at a lower level.

Let us relate the diffusion of the car to our frameworks of multiplication and diffusion. The phrase "keeping up with the Jones" often referred to buying a stylish new car to maintain status with the next-door neighbors. The phrase said social fibers were carrying messages. Nevertheless, recall the multiplying tasks for achievement. First, cars cost money. Then the driver's test must be passed. Many innovations cannot diffuse until a parallel chain of conditions also adapts. Clearly, cars require paved roads, gasoline, and licenses as well as manufacturing, distribution, and repair. So cars will take time to diffuse, the numerous links to be hooked together causing a long-tailed distribution of density and saturation levels as well.

Arnulf Gruebler [3] analyzed the first century of the auto in 13 diverse countries (Fig. 5). Graphically, the outcome of nations building an auto system resembles an individual making money or writing scientific papers. Both auto saturation levels and diffusion times vary internationally by an order of magnitude. The reason for the faster diffusion among latecomers is simple. The lessons learned by the first adopters raise the probability of putting the links together. Catching up becomes easier because others have shown what the links in the chain are and how to connect them. Returning to autos and Fig. 5, one sees Mexico well below the line for saturation level. It has about one-third the saturation density that would put it in line. Plotted on the same graph, Brazil, too, would park below the line. My interpretation is that the line is right, and our calculation in a sense is wrong. Taking one-third of the population of Mexico or Brazil for the denominator of cars per capita would bring both into line. That would mean two-thirds of the Mexicans and Brazilians are below the wolf point for autos, so to speak. Other national "neighborhoods" in Fig. 5 fall into line.

The saturation level may decline because the first adopters overshoot. British (and Americans too) extended costly rails to small communities whose traffic did not pay. As later happened with cars, rails diffused around the world according to the general rule that late adopters tend to develop less. During the time box of 1885-1940, India, China, and Mexico fit the pattern perfectly. India, starting early, laid about three times as many rails as China, which laid about twice as many as latecomer Mexico [20,21]. With time, of course, substitutes such as autos for rails and planes for autos can lower the profitable density. The appearance of replacements is one of the rules of the game. Cars displaced railroads, which peaked in the 1920 s as the predominant means of mobility. Although the oily epoch of the auto after World War II seemed different from the steamy epoch of rail, still the diffusive, skewed game of successive tasks and a skewed outcome played out the same, as I believe it will during the new millennium.

Electricity generation has also expanded within time boxes and promises to do so again, to power the proliferating information devices and eventually transport [22]. Comparing two past pulses of power generation, we find America peaked in 


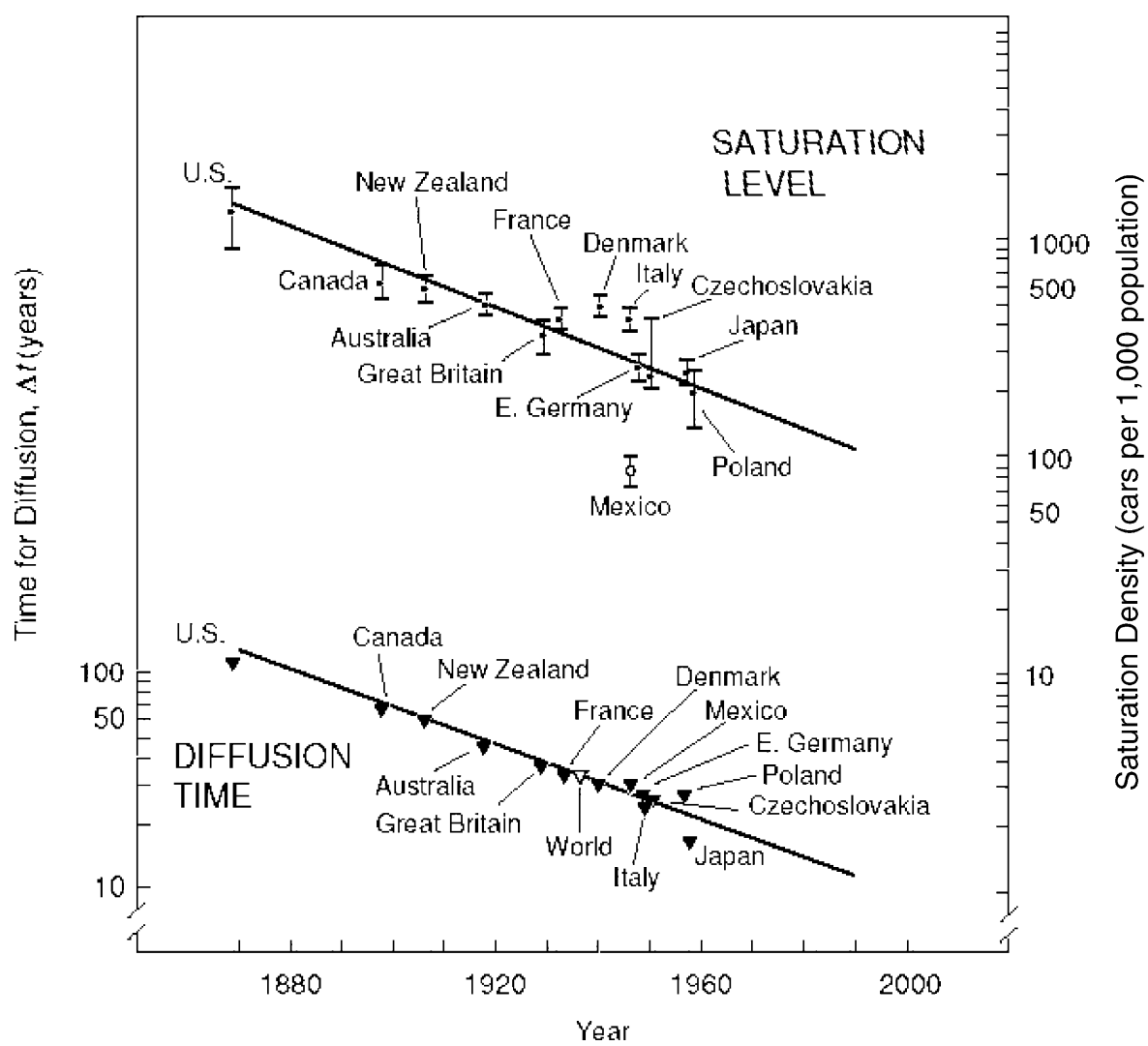

Fig. 5. Speed and level of passenger car diffusion in diverse countries. In Canada, for example, diffusion began in about 1900 and required about 60 years (lower part of chart) and reached about 500 cars per 1000 population (upper part of chart). Source: Gruebler [3].

1929 and again in 1970, while Brazil peaked in 1940 and then 1981. Though Brazil developed more steeply, the saturation level—now almost $3000 \mathrm{TW}$ h in America but only $300 \mathrm{TW} \mathrm{h}$ in Brazil — differs by an order of magnitude, while population differs less than twofold. Standardization is usually one of the multiplicative links during widespread diffusion. Brazil has yet to standardize electrical current fully. In Rio de Janeiro and São Paolo, the voltage has been mostly 110 or 120 and in Salvador and Manaus 127, but in Recife, Brasilia, and elsewhere 220.

Nuclear reactors make about $20 \%$ of electric power worldwide. Although often labeled exceptional, nuclear generation has grown in the familiar way, with a skewed set of accelerating diffusions. America, starting early, needed about 25 years to build the bulk of its fleet, while alert follower France did the job in about half that time.

Railroads, autos, and nuclear power plants entered seemingly different societies a couple of generations apart. In 1830, when George Stephenson's steam locomotive 
The Rocket began the rail boom with service between Liverpool and Manchester, most British workers farmed, and bridal couples rarely could sign their licenses. Around 1890, when Daimler and Benz developed the prototype of the auto, women did not vote, and monarchs reigned over most of Europe. In 1957, when the first commercial nuclear power plant opened in Shippingport, Pennsylvania, the US and the USSR were warring coldly, and European colonial empires were crumbling inevitably. Yet the outcomes of these innovations differed little: skewed a long way from the early innovators back to where most lived, still scarcely affected.

\section{A golden ideal?}

Having presented persistent reasons for skew, even in a broadband world, I now speculate about an idealized view. To the human eye, perhaps nothing is more ideal than the "golden rectangle", whose length and width are the segments of a line divided according to the golden ratio of 1.62:1. Leonardo arranged his work with this "divine proportion". It occurs in widely varying areas of Mathematics, as in the Fibonacci sequence of numbers formed by adding successive members in a series to find the next member: $0,1,1,2,3,5,8,13 \ldots$ Fibonacci exemplified his numbers as the pairs of rabbits increasing when offspring joined parents. The ratios of successive values $2 / 1,3 / 2,5 / 3,8 / 5,13 / 8$ approach the golden ratio. The ratio describes petals of flowers, seed in seed heads, and shells of snails $[23,24]$.

Imagine a sequence of innovations diffusing and growing logistically. Let the delay before the second wave be $1 / 1.62$, before the third be $1 / 1.62$ before the second, and so on. Let the second wave grow toward a limit $1 / 1.62$ of the limit of the first and the third toward a limit of 1/1.62 the limit of the second, and so on. Fig. 6 represents these hypothetical diffusions according to the golden ratio, and Fig. 7 replots the same processes according to their rates and saturation densities.

More than petals, seeds, and shells encourage my raising the golden ratio here. In 1920, at the peak flowering of the railway era, the mileage of track in America was 1.6 times that of Europe, and the mileage in the rest of the world outside America was 1.6 times that of America. We lack adequate hindsight to place a date on the peak of the auto era, but in 1986-1987, the number of passenger autos outside America was 1.67 times that of American (and rising). As an idealist, I would place the auto peak in the mid-1970s, when the ratio was golden, and the real cars of Fig. 5 and ideal objects of Fig. 7 match.

Haegerstrand cautioned that physical space may sometimes obscure our ability to see the more important social space. Demographer Nathan Keyfitz, for example, speaks of a world middle class whose behaviors are consistent [25]. I would wager that if we recognized the true social borders of the world and collected data accordingly, the ratios plotted would very often be golden.

But will instant messaging end the Golden Era? At first full blush of the Internet, as of December 1, 1997, 61\% of all websites were in the US, about this fraction of US sites were in California, and about the same fraction of California sites were in the San Francisco Bay area. The new web we are weaving resembles those of yore (Fig. 8). A few sites have large numbers of pages and most sites few, and a 

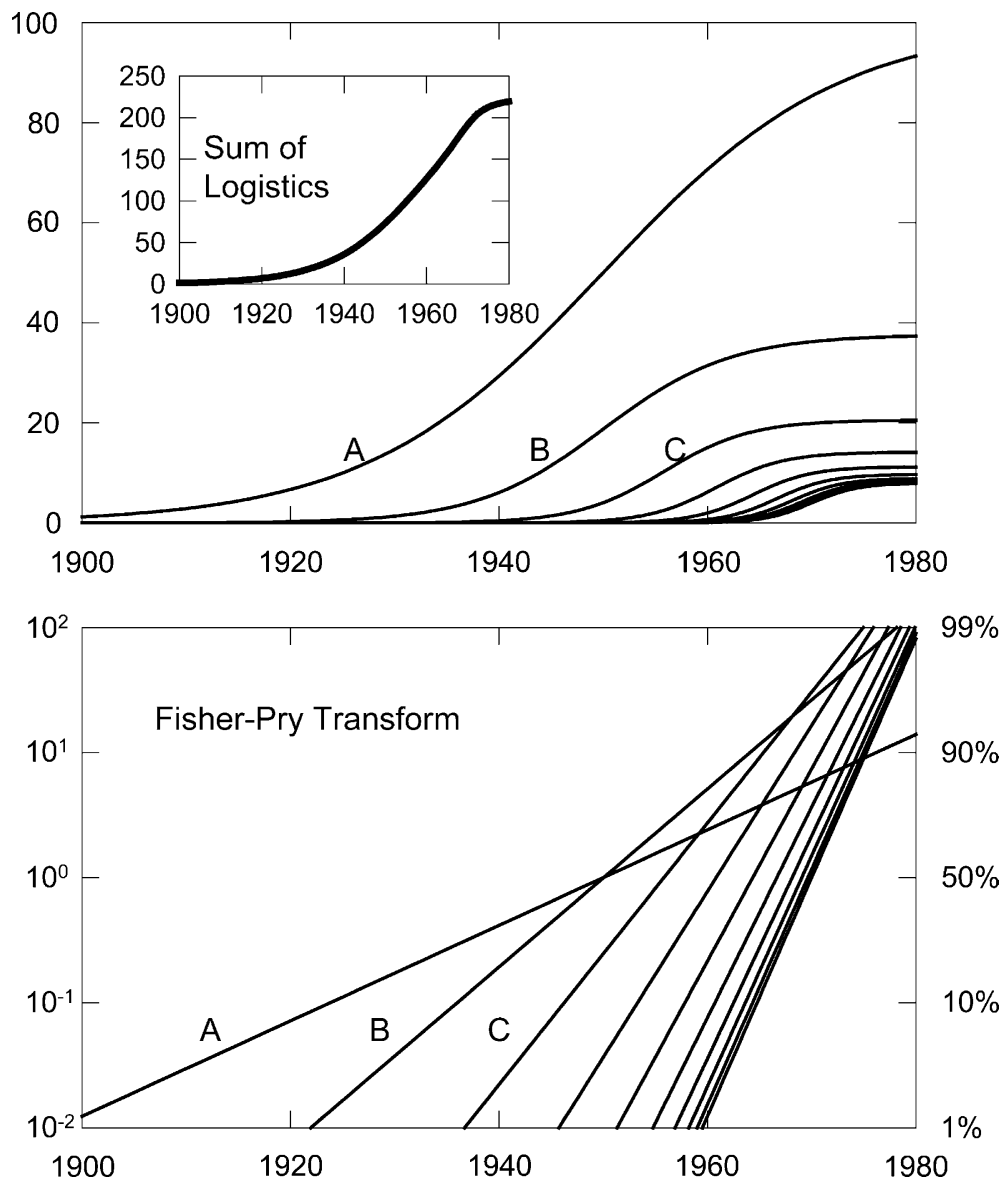

Fig. 6. Logistic diffusion with golden ratios. The charts show an idealized "technology" diffusing into societies A, B, C, and so on with hastening frequency according to the golden ratio and lessening saturation level, also according to a golden ratio. The inset in the upper panel shows the "global" sum of all the "national" diffusion processes. The lower panel shows the linear or Fisher-Pry transform.

few sites are heavily frequented and most hardly at all. A few places concentrate most sites, the ratios all in classical order [26,27].

Brief speculation about cause for the golden presence is irresistible. Physicist Cesare Marchetti (personal communication) proposes an analogy between the redistribution of income between different levels and the redistribution of electrons between different states in an atom. When the free parameter, temperature (or GDP), rises, more electrons (or incomes) enter in the higher states. Independent of the initial distribution, the "final" one will always be the same and maximizes entropy, playing on statistics and probability. Scale-independent and reducible to fractals, the golden ratio appears particularly good for growing systems because it preserves the rules. 


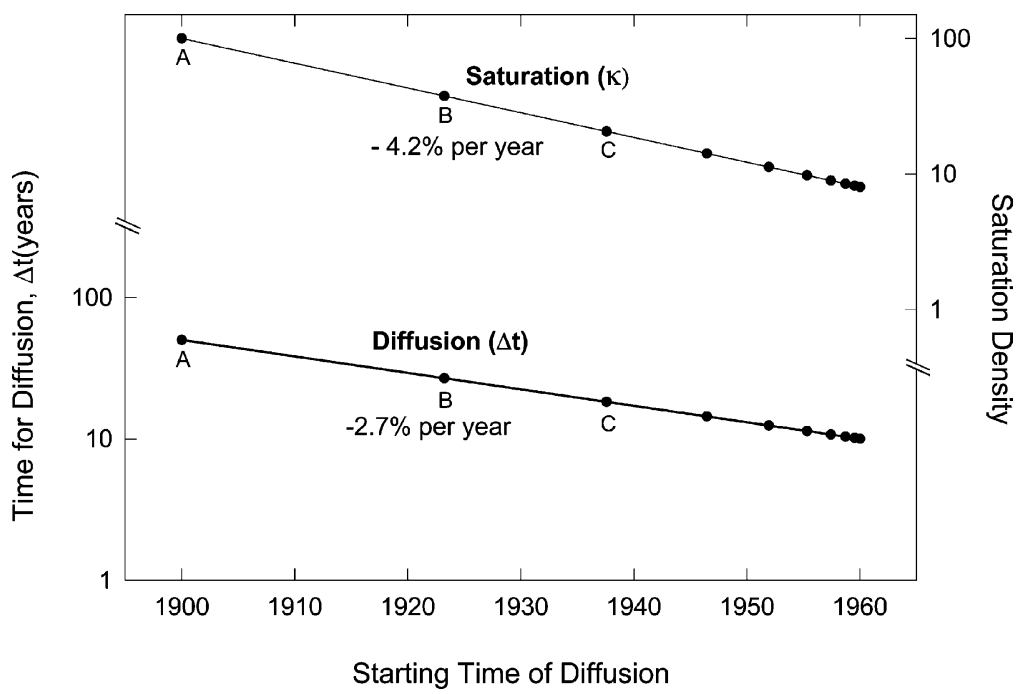

Fig. 7. Changes in diffusion and saturation rates for a hypothetical technology introduced at successive golden intervals. In this case, for each year the society waits to begin adoption, the society adopts $2.7 \%$ per year faster and saturates $4.2 \%$ lower. In short, late adopters adopt faster and leaner.

Whatever the cause, the ubiquitous nature of the golden ratio and the experience of latecomers arriving at shorter and shorter intervals and rising to lower and lower limits support Fig. 6 as an idealized model of diffusion. It provides a graphic answer to the second question: "Even with instant communication and swift transport, incomes will not grow equal."

\section{If not like Americans, what will the people of the world live like?}

My story began with the hope of many that all the world would someday live like its top consumer, achieving material well-being as well as equity. Then I described the fear of others that the rest of the world will do just that-live like Americans.

The history of incomes and the failure of transport and communication to equalize them, we now see, dims the hope for both high and equal income. Fortunately a dimming hope for high and equal income does not condemn the poor to live as they do now. As the years passed, along the axis of Fig. 2, the lowest incomes did continue lagging behind the richest. Nevertheless, the incomes of the poor climbed far, and transfer payments and taxes can tailor the tails to meet the values and ensure the tranquility of the society.

The rise of both high and low incomes, of course, irresistibly lifts the global sums of income, net production, and the capacity to consume more. This prospect of a rising global sum of income heightens the fear of those who expect the global sum of environmental impact to rise in lockstep with population and income. Is there any chance population can rise and incomes multiply while harming the 


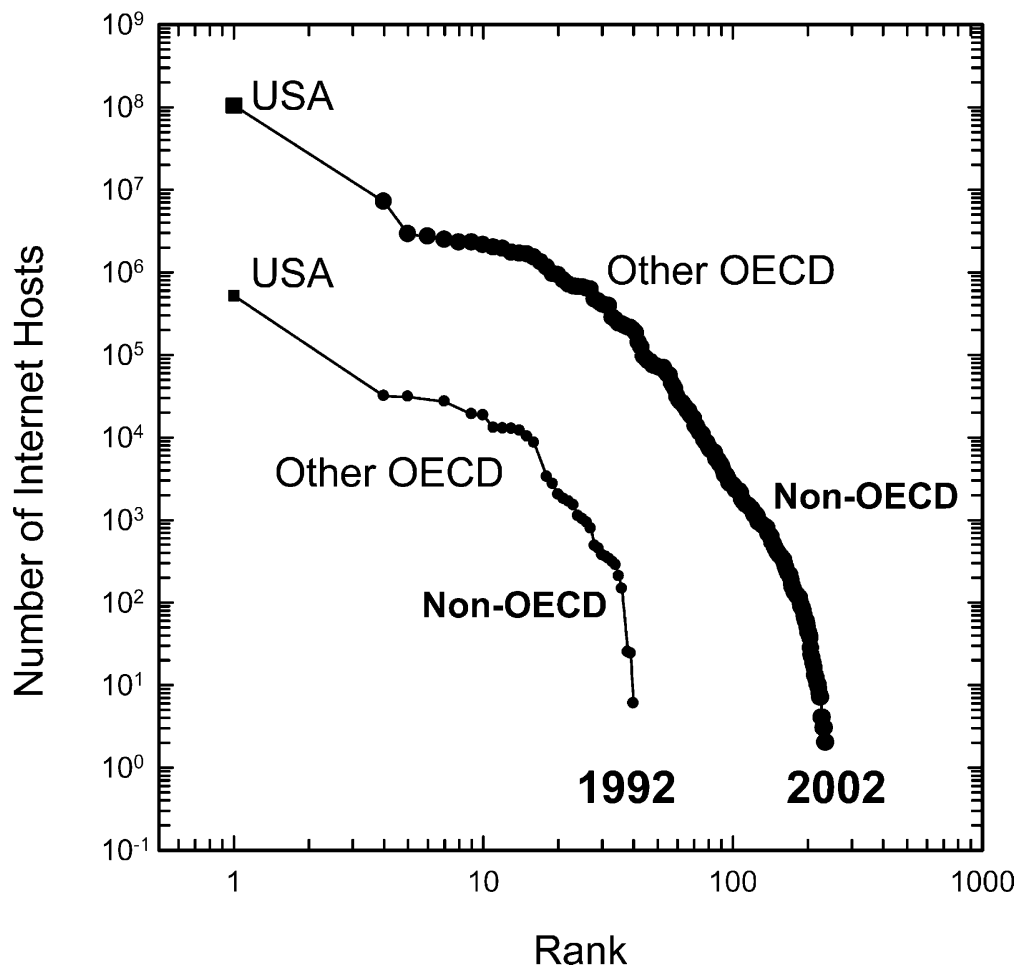

Fig. 8. Number of Internet hosts by domain location. The web shows a typically skewed distribution. The top 20 domain locations account for more than $90 \%$ of all hosts. Note little change in pattern between 1992 and 2002. Sources: 1992 survey by M. Lottor www.ripe.net/ripe/mail-archives/ripe-list/ 1992/msg0015.html; 2002 survey by Internet Software Consortium www.isc.org/ds/.

environment less? If dollars and harm rise in a viselike ratio, a rising global sum of dollars is an environmental disaster.

In the time it takes for diffusion, however, there is a chance to escape this seeming vise [28]. During the grace period of diffusion, economic power, public ethics, and the rules and technology for avoiding environmental harm can improve to lessen side effects. In the early 20th century, America had far the most horses for transport of any nation, about 20 million. Had the 20 million horses multiplied 10fold to the 200 million motor vehicles now in America, the stink of manure and buzzing of flies would have created an unbearable environment. But horses did not multiply to 200 million in America, nor did other nations ever saddle up and hitch up to ride like Americans. The car stretched mobility without manure and flies, and improvements continued until the car of 2000 emits only about $5 \%$ of the regulated pollutants of the car of the early 1970s.

The next pulse of expanded mobility may well populate the world with a billion personal vehicles (about 1.6 times the present level), but the cars made decades hence will be powered differently. A flurry of activity involving automotive and 
other companies points to cars powered by hydrogen, fed directly into an engine or into a fuel cell. Fuel cells produce electricity through an electrochemical process that combines hydrogen with oxygen from the air, emitting water and little else. Cars may crowd more roads, but the air should be clean. China can have present American mobility without present American cars.

Well before Chinese consume today's per capita American electricity, innovative plants burning natural gas at very high temperatures and pressures can generate it. Preliminary studies suggest the plants are thermodynamically feasible and could achieve efficiency about $75 \%$ better than today as well as zero emissions, with the $\mathrm{CO}_{2}$ safely bled off for sequestration back in Earth [29]. Elsewhere, we have made the case that continuing to lift yields by $1-2 \%$ per year in farming and forestry can provide the goods for growing incomes and populations while sparing acres of fields and woods [30].

When average per capita incomes double worldwide, probably 30-50 years hence, most of today's goods affecting environmental quality, whether auto engines or power plants, will be as obsolete as horseback and gristmill, replaced by environmentally superior ones. Even America did not buy Britain's rails, nor will the rest of the world buy America's cars. The successive development of each individual society, its ontogeny, does not recapitulate the technical life history of the whole human tribe, our phylogeny.

\section{Conclusion}

Forced by a judge to answer with a simple "yes" or "no" whether the rest of the world will live like America, I would be compelled by history to answer "no". I would, however, ask the reader a few more moments to review my reasons and finally accept one sentence rather than one word for the answer.

Neither all nations nor all individuals have ever lived at the income of the top consumer, America's predecessors or itself. Not only have incomes varied across the world and within nations, but it takes a skewed distribution with wide variability to fit them. The multiplication of the probabilities of linking the successive rings of a chain of difficult tasks skewed the distribution of the successes of complex achievements and keeps incomes skewed. No wonder everyman dreaming of a crown chooses simply to buy a lottery ticket rather than to try to link eight rings improbably in a chain.

One might hope that swift and cheap transport and instant communication would lessen inequality and skewness, homogenizing income around the world. Social wrinkles have, however, maintained the variation, broad and skewed.

Other countries may leap over America to the lead, as America has jumped over other leaders throughout history. Britain built a denser net of rail than America, but Rockefeller's Standard Oil and Ford's Model T propelled America ahead in autos. Although history predicts new leaders will pass America in its turn, the concentration of websites in California suggests no change of leaders will happen soon. 
With apologies to John (xii, 8), "For the [relatively] poor always ye have with you." History predicts even small differences of ability, energy, education, inheritance, saving, and taking of risk will maintain skewness despite taxes and transfer payments, within societies and internationally. Redistribution of wealth can keep the wolf from the door and change appearances, a matter of extreme importance, but not the underlying tendency to skew.

History also predicts a greater global sum of income, which in turn could lift a greater global sum of environmental harm in lockstep. As incomes rise with time, however, changed consumption diffuses only slowly. It is sticky. During that grace period between the rise of income and consumption, economic, social, and environmental requirements and capacities can grow to lessen harmful side effects. When per capita incomes average double those of today a generation or two hence, most of today's goods determining environmental quality, whether auto engines or power plants, will be obsolete, replaced by environmentally superior ones. When China has today's American mobility, it will not have today's American cars. So, the answer to my question is that we are likely to live in a cleaner world, with golden inequalities.

\section{Acknowledgements}

Arnulf Gruebler, Dale Langford, Perrin Meyer, Woollcott Smith, Chauncey Starr, Paul Waggoner, Kurt Yeager are gratefully acknowledged.

\section{References}

[1] Cerf C, Navasky V. The experts speak: the definitive compendium of authoritative misinformation. New York: Pantheon; 1984.

[2] Scarre C. The Penguin historical atlas of ancient Rome. New York: Viking; 1995.

[3] Gruebler A. The rise and fall of infrastructures: dynamics of evolution and technological change in transport. Heidelberg, Germany: Physica; 1990.

[4] Zipf GK. Human behavior and the principle of least effort. Cambridge, MA: Addison-Wesley; 1949.

[5] Li W. Zipf's law everywhere. Glottometrics 2003;5:14-21.

[6] Pareto V. Cours d'economie politique. Lausanne; 1897.

[7] Johnson NO. The Pareto law. The Review of Economic Statistics 1937;19:20-6.

[8] Milanovic B. True world income distribution, 1988 and 1993: first calculation based on household surveys alone. World Bank, Development Research Group; October 1999. Available from: http:// www.worldbank.org/research/transition/pdf/world2x1b.pdf.

[9] Shockley W. Proceedings of IRE 1957;45:279-90.

[10] Lotka AJ. The frequency distribution of scientific productivity. Journal of the Washington Academy of Sciences 1926;16(12):317-23.

[11] de Solla Price D. Little science, big science ... and beyond. Columbia, New York; 1986. p. 30-55.

[12] Martell RF, Lane DM, Emrich C. Male-female differences: a computer simulation. American Psychologist 1996; February:157-8.

[13] Montroll EW, Badger WW. Introduction to quantitative aspects of social phenomena. Gordon and Breach; 1974.

[14] West BJ, Deering B. The lure of modern science: fractal thinking. Singapore: World Scientific; 1995. 
[15] Haegerstrand T. Innovation diffusion as a spatial process. Chicago: University of Chicago Press; 1967 [first published in Swedish in 1953].

[16] Mintzberg H. Mintzberg on management: inside our strange world of organizations. New York: Free Press; 1989.

[17] Dunbar RIM. Grooming, gossip, and the evolution of language. Cambridge, MA: Harvard University Press; 1997.

[18] Schumpeter JA. Business cycles: a theoretical, historical, and statistical analysis of the capitalist process, vols. I and II. New York: McGraw-Hill; 1939.

[19] Marchetti C. Fifty-year pulsation in human affairs: analysis of some physical indicators. Futures $1986 ; 17(3): 376-88$.

[20] Mitchell BR, editor. International historical statistics: Africa, Asia and Oceania 1750-1993. International historical statistics series. London: Palgrave Macmillan; 1998.

[21] Mitchell BR, editor. International historical statistics: the Americas 1750-1993. International historical statistics series. London: Palgrave Macmillan; 1998.

[22] Ausubel JH, Marcheti C. Elektron: electrical systems in retrospect and prospect. In: Ausubel JH, Langford HD, editors. Technological trajectories and the human environment. Washington, DC: National Academy Press; 1997, p. 110-34.

[23] Philippou AN, Bergum GE, Horadum AF. Fibonacci numbers and their applications. Dordrecht: Reidel; 1986.

[24] Ghyka MC. Le nombre d'or. Paris: Gallimard; 1959.

[25] Keyfitz N. World resources and the world middle class. Scientific American 1976;235(July):28-35.

[26] Huberman BA. The laws of the web: patterns in the ecology of information. Cambridge, MA: MIT Press; 2001.

[27] Gruebler A. Digitally divided: the temporal and spatial diffusion of the Internet. Journal of Environment and Development, in press.

[28] Waggoner PE, Ausubel JH. A framework for sustainability science: a renovated IPAT identity. Proceedings of the National Academy of Sciences USA 2002;99(12):7860-5.

[29] Ausubel JH. Some ways to lessen worries about climate change. The Electricity Journal 2001;14(1):24-33.

[30] Ausubel JH. The great reversal: nature's chance to restore land and sea. Technology In Society 2000;22:289-301.

[31] Griliches Z. Hybrid corn: an exploration in the economics of technological change. Econometrica 1957;25:501-22.

Jesse Ausubel directs the Program for the Human Environment (phe.rockefeller.edu) at The Rockefeller University, where he has worked since 1989. His work elaborates the technical vision of a large, prosperous society that emits little or nothing harmful. Mr. Ausubel helped formulate the World Climate Program, Global Change Program, and the field of Industrial Ecology and co-chaired the US Council on Foreign Relations' forum on the World Summit for Sustainable Development. 